\title{
Erratum to: Country-Level Socioeconomic Indicators Associated with Healthy Life Expectancy: Income, Urbanization, Schooling, and Internet Users: 2000-2012
}

\author{
Jong In Kim ${ }^{1,2} \cdot$ Gukbin Kim $^{3}$
}

Published online: 23 March 2016

(C) Springer Science+Business Media Dordrecht 2016

\section{Erratum to: Soc Indic Res \\ DOI 10.1007/s11205-015-1107-2}

Unfortunately in the original publication of the article, the second affiliation of the corresponding author and the acknowledgment were published incorrectly.

The corrected second affiliation and the acknowledgment are given in this erratum.

Acknowledgments The authors would like to thank three reviewers for their valuable comments, which helped to improve this manuscript significantly. This paper was sponsored by Wonkwang University in 2016.

The online version of the original article can be found under doi:10.1007/s11205-015-1107-2.

Jong In Kim

kji122@wku.ac.kr

Gukbin Kim

gukb.kim@gmail.com

1 Division of Social Welfare and Health Administration, Wonkwang University, Iksan, Republic of Korea

2 Institute for Longevity Sciences, Wonkwang University, Iksan, Republic of Korea

3 Management with International Business, Royal Holloway, University of London, London, UK 